\title{
Complications of Extended Endoscopic Endonasal Surgery in Elderly Patients
}

\author{
Tyler J. Kenning ${ }^{1}$ Carlos D. Pinheiro-Neto ${ }^{2}$
}

\begin{abstract}
Address for correspondence Tyler ]. Kenning, MD, FAANS, Department of Neurosurgery, Albany Medical Center, $47 \mathrm{New}$ Scotland Avenue, MC-10, Albany, NY, United States (e-mail: kennint@mail.amc.edu).
\end{abstract}

J Neurol Surg B 2018;79(suppl S3):S287-S288.

\begin{abstract}
Keywords

- endoscopic

- endonasal

- pituitary adenoma

- subdural hematoma

- elderly

- complication

Extended endoscopic endonasal procedures are not unique among surgical interventions in carrying increased risk in the elderly population. There are, however, components of the procedure, namely high-flow cerebrospinal fluid leaks, that do result in the potential for increased perioperative morbidity for these patients. We present the case of a 77-year-old male with a large invasive pituitary macroadenoma resected through a transplanum-transtuberculum-transsellar endonasal approach. A gross total resection was obtained with resolution of the patient's preoperative ophthalmologic deficits. One month postoperatively, the patient developed progressive lethargy and cranial imaging demonstrated a left convexity subacute subdural hematoma. This was evacuated through a twist drill craniostomy. Despite measures to limit the operative time of the initial endonasal procedure as well as the absence of a postoperative cerebrospinal fluid fistula, the patient still developed this complication. Along with more typical potential causes of postoperative decline following extended endonasal procedures, problems from high-flow intraoperative cerebrospinal fluid leaks alone can result in morbidity in the elderly population. This should be acknowledged preoperatively and a high suspicion should exist for the presence of intracranial hemorrhage in these patients with any postoperative deficits. Additional intraoperative measures can be utilized to minimize such risks.

The link to the video can be found at: https://youtu.be/EkLmt2T8_UE.
\end{abstract}

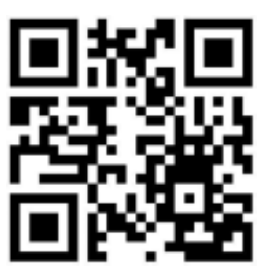

received

October 17, 2017

accepted

December 12, 2017

published online

February 8, 2018 www.thieme.com/skullbasevideos

www.thieme.com/jnlsbvideos
DOI https://doi.org/

10.1055/s-0038-1625948. ISSN 2193-6331.
๑) 2018 Georg Thieme Verlag KG
Stuttgart · New York

License terms

(c) $(1) \$$ 


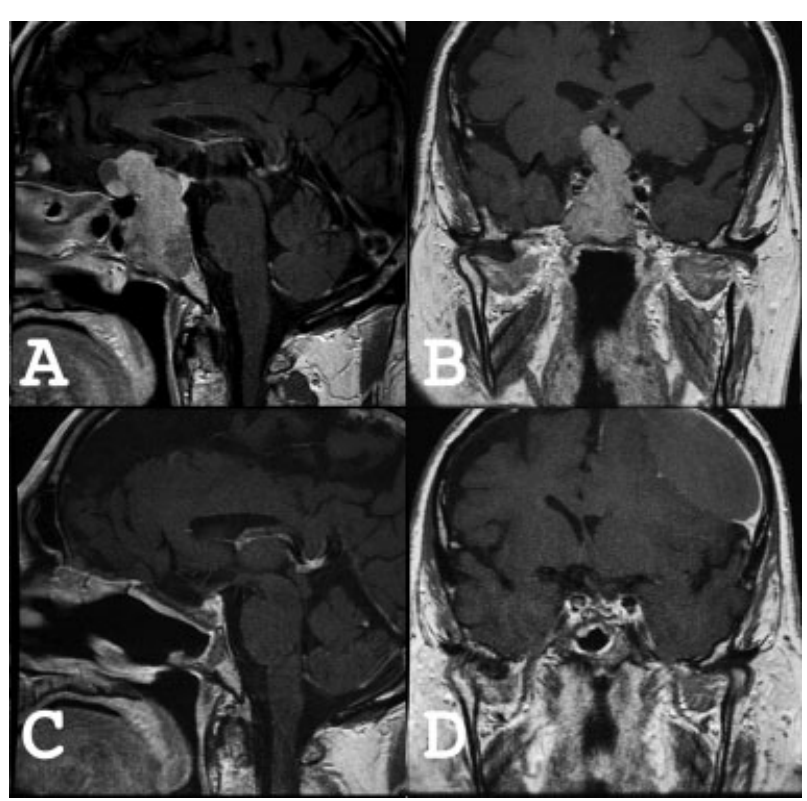

Fig. 1 Preoperative (A) sagittal and (B) coronal magnetic resonance imaging (MRI) showing a large invasive pituitary macroadenoma. Postoperative (C) sagittal and (D) coronal MRI at 3 months showing gross total resection of the tumor and a large left frontal convexity subdural hematoma.

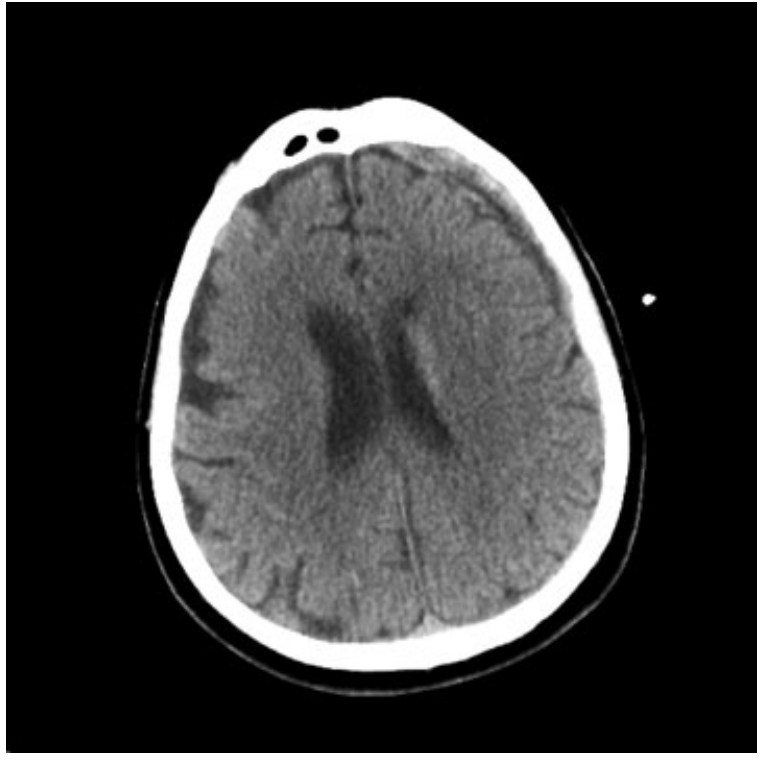

Fig. 2 Cranial computed tomography (CT) at 6 months postoperatively showing a small residual left frontal convexity subdural hematoma after evacuation. 